\title{
Analisis Penerapan Kendali Otomatis berbasis PID terhadap pH Larutan
}

\author{
FEBRIAN HADIATNA, ALFI DZULFAHMI, DECY NATALIANA \\ Teknik Elektro Institut Teknologi Nasional Bandung, Indonesia \\ Email: febrian_hadiatna@yahoo.com
}

Received 20 Februari 2019 | Revised 8 Juli 2019 | Accepted 27 Januari 2020

\begin{abstract}
ABSTRAK
Nilai $\mathrm{pH}$ pada larutan nutrisi tanaman hidroponik merupakan salah satu parameter penting agar tumbuhan berkembang dengan baik. Salah satu metode pengendali otomatis adalah menggunakan pengendali PID. Penelitian ini bertujuan untuk menganalisis penerapan sistem pengendali $\mathrm{pH}$ larutan nutrisi menggunakan PID. Proses pengendalian diatur oleh larutan $\mathrm{pH}$ up dan larutan $\mathrm{pH}$ down. Pengujian pengendali PID terdiri dari pengujian pengendali Propotional $(P)$, pengendali Propotional-Inrtegral (PI), dan Propotional-Integral-Derivative (PID). Hasil pengujian dengan menggunakan metode tunning trial and error diperoleh hasil pengendali Propotional menghasilkan respon lebih baik dengan nilai $K p=1$, hasil yang didapat sistem tidak mengalami overshoot/undershoot dengan waktu yang dibutuhkan mencapai titik kesetimbangan di setpoint yaitu 126 detik. Agar sistem terjaga dinilai setpointnya sistem pengendali akan bereaksi terhadap perubahan error, sehingga memerlukan lebih banyak larutan $\mathrm{pH}$ up dan $\mathrm{pH}$ down.
\end{abstract}

Kata kunci : Hidroponik, pH, Arduino, kendali PID.

\begin{abstract}
The $\mathrm{pH}$ value of hydroponic-plants nutrient solution is one of the important parameters for plants to grow up well. This study aims to analyze the application of a system to control the $\mathrm{pH}$ of nutrient solutions using PID which is controlled by a $\mathrm{pH}$ up solution and a $\mathrm{pH}$ down solution. PID controller testing consists of Propotional (P) control test, Propotional-Inrtegral (PI) controller, and PropotionalIntegral-Derivative (PID) controller. The test results obtained using the tunning trial and error method obtained a Propotional controller result have a better response with the value $K p=1$, the system does not overshoot / undershoot. the time needed to reach a stable value at setpoint is 126 seconds. so that the system is maintained at its set point the control system will react to error changes, that is why it requires more $\mathrm{pH}$ up liquid and the $\mathrm{pH}$ liquid down.
\end{abstract}

Keywords : Hydroponic, pH, Arduino, PID controller. 
Hadiatna, dkk

\section{PENDAHULUAN}

Teknik budi daya tanaman dengan metode hidroponik merupakan sebuah alternatif untuk mendapatkan tanaman sayuran dan buah-buahan di lahan yang terbatas. Sistem hidroponik adalah metode budi daya tanaman dengan menggunakan air sebagai media tanamnya (Roidah, 2014). Metode ini sangat cocok bagi masyarakat perkotaan yang umumnya memiliki lahan yang terbatas. Air yang digunakan pada tanaman hidroponik sudah diberikan nutrisi sesuai kebutuhkan tanaman, sehingga tanaman akan tumbuh secara optimal. Terdapat 6 faktor utama yang mempengaruhi pertumbuhan tanaman hidroponik, diantaranya kualitas air yang digunakan, cahaya, oksigen, nutrisi, suhu dan $\mathrm{pH}$. Seluruh faktor utama tersebut perlu dilakukan proses pemantauan. Namun dengan kesibukan orang perkotaan yang tidak dapat selalu memantau langsung kondisi tanaman di greenhouse, pemilik disulitkan dalam pemantauan kondisi tanaman hidroponik jika mengalami kondisi ketidaksesuaian $\mathrm{pH}$, suhu, kelembaban dan kepekatan nutrisi().

Pada penelitian ini, akan mengambil salah satu faktor yang mempengaruhi pertumbuhan tanaman hidroponik yaitu kadar $\mathrm{pH}$ larutan. $\mathrm{pH}$ didefinisikan sebagai logaritma basa negatif 10 konsentrasi ion hidrogen. Namun, karena sebagian besar reaksi kimia dan biologis diatur oleh aktivitas ion hidrogen, definisi tersebut dengan cepat diubah (Shahrulakram, 2016). Ada beberapa faktor yang mempengaruhi nilai $\mathrm{pH}$ larutan nutrisi pada tanaman hidroponik yaitu, proses fotosintesis, suhu, respirasi, bakteri, dan media tanam. PH yang dibutuhkan tanaman berkisar 6 hingga 7 derajat keasaman, tergantung jenis tanamannya (Mitalom, 2018)(Lee, 2015).

Pada tahun 2017, Sudewa telah melakukan penelitian mengenai pengukuran terhadap $\mathrm{pH}$ larutan. Dari hasil penelitiannya tersebut diketahui bahwa dalam kurun waktu 1 jam sekali nilai $\mathrm{pH}$ air mengalami perubahan nilai sebesar 0,01 hingga 0,02 untuk jumlah volume larutan yang kurang dari 1 Liter (Sudewa, 2017). Berdasarkan faktor-faktor tersebut perlu adanya proses pengendalian $\mathrm{pH}$ secara berkala. Secara umum para pelaku pembudi daya tanaman hidroponik melakukan pengendalian $\mathrm{pH}$ secara manual, sehingga dengan cara tersebut pengendalian yang dilakukan hanya pada waktu tertentu saja. Berdasarkan hal tersebut, perlu adanya pengendalian secara otomatis dan besifat kontinu. Penerapan sistem pengendali otomatis ini dapat mempermudah pengendalian $\mathrm{pH}$ larutan tanaman dan sebagai bentuk penerapan teknologi pada bidang agrikultur.

Tahun 2015, Saaid beserta timnya telah melakukan penelitian, dengan mengimplementasikan suatu sistem pengendali nilai pH suatu nutrisi (Saaid, dkk. 2015). Dalam penelitian tersebut dijelaskan perancangan sistem kendali $\mathrm{pH}$ larutan nutrisi secara otomatis menggunakan Arduino Mega sebagai unit proses, sensor $\mathrm{pH}$ sebagai unit input, dan motor servo sebagai unit output. Sistem ini bekerja secara otomatis dengan cara membandingkan nilai $\mathrm{pH}$ yang diukur dengan nilai $\mathrm{pH}$ set point, selanjutnya apabila nilai $\mathrm{pH}$ tidak sesuai dengan nilai set point maka mikrokontroler akan memberikan sinyal pada motor servo untuk memberikan larutan $\mathrm{pH}$ up atau $\mathrm{pH}$ down. Sistem yang digunakan adalah sistem kontrol on/off, pengendalian ini berkerja pada dua posisi, yaitu kondisi "or" atau "off'. Sistem pengendalian ini memiliki beberapa kekurangan yaitu sering terjadi perubahan dari on ke off, atau sebaliknya, sehingga dapat pempercepat kerusakan pada sistem. 
Selanjutnya, penelitian dengan judul "Optimal PID Control of pH Neutralization Plant", oleh Kishore Bingi berserta timnya (Bingi, dkk. 2016). Penelitian ini membahas perancangan matematis PID dengan metode Zn (Ziegler-Nichols) dan metode PSO (Particle Swarm Optimization). Perancangan ini diperuntukkan untuk mengatur $\mathrm{pH}$ di industri menggunakan kurva tirasi. Kesimpulan yang diperoleh pada penelitian ini menunjukkan metode PSO (Particle Swarm Optimization) lebih baik dibandingkan metode ZN (Ziegler-Nichols).

Kemudian, tahun 2016 dilakukan penelitian dengan judul "Implementation of Real-Time Fuzzy Logic Control for NFT-Based Hydroponic System on Internet of Things Environment", mengenai implementasi pengendalian $\mathrm{pH}$ dan EC (Electrical Conductivity) menggunakan pengendali Fuzzy-Logic oleh Desta Yolanda berserta timnya (Yolanda, dkk. 2016). Penenelitian ini bertujuan untuk mengendalikan nilai $\mathrm{pH}$ dan EC pada larutan nutrisi hidroponik dengan menggunakan sistem NFT (Nutrient Film Technique). Hasil penelitian ini adalah setiap $1 \mathrm{ml}$ larutan alkaline dapat menaikkan nilai $\mathrm{pH}$ sebesar $\pm 0,01$ pada 10 liter larutan dalam tangki, dan dengan menambahkan $1 \mathrm{ml}$ larutan acid dapat menurunkan nilai $\mathrm{pH}$ sebesar $\pm 0,015$ pada $10 \mathrm{~L}$ tangki larutan. Pada sistem yang dibuat semakin besar kenaikan dan penurunan $\mathrm{pH}$ maka semakin lama waktu respon sistem untuk menyelesaikan proses dalam memenuhi masukan yang diinginkan.

Berdasarkan dari beberapa referensi tersebut, maka dalam penelitian ini akan dilakukan analisis sistem kendali larutan pH dengan metode pengendali PID. Rumusan masalah yang diambil dalam penelitian ini yaitu bagaimana menerapkan pengendali PID untuk mengatur $\mathrm{pH}$ larutan nutrisi, serta berapa nilai $\mathrm{Kp}, \mathrm{Ki}$, Kd yang digunakan pada sistem tersebut, dan menghitung lama waktu yang dibutuhkan untuk mencapai kesetimbangan sistem.

Penelitian ini dibatasi dengan menggunakan sensor pH tipe SEN0161. Metode mencari nilai $\mathrm{Kp}, \mathrm{Ki}$, dan $\mathrm{Kd}$ menggunakan metode trial and error, nilai $\mathrm{pH}$ yang akan diatur dibatasi yaitu sebesar 6,5 derajat keasaman, tidak membahas tentang pengaruh terhadap pertumbuhan tanaman, pengujian dilakukan di dalam ruangan, dan suhu ruangan dalam pengujian dianggap sama yaitu berkisar $20^{\circ} \mathrm{C}$ sampai $30^{\circ} \mathrm{C}$, nilai tersebut masih di dalam range yang diperbolehkan. Plant yang diuji tidak menggunakan larutan nutrisi tanaman, melainkan disimulasikan dengan menggunakan air mineral.

\section{PERANCANGAN DAN REALISASI SISTEM}

Perancangan sistem kendali $\mathrm{pH}$ larutan yang dirancang menggunakan perangkat keras dan perangkat lunak. Perangkat keras yang digunakan terdiri dari 3 sub-sistem yaitu bagian input unit, process unit, ouput unit, dan feedback unit. Input unit terdiri dari Personal Computer(PC) yang akan mengatur nilai set point. Process unit terdiri dari mikrokontroler ATmega328. Output unit terdiri dari modul driver motor, pompa peristaltik, dan Personal Computer (PC). Perangkat lunak dirancang agar dapat membaca nilai $\mathrm{pH}$ melalui sensor, mengolah data, melakukan pengendalian $\mathrm{pH}$, dan menampilkan data pada PC. Gambar 1 menunjukkan diagram blok pengendali PID. 


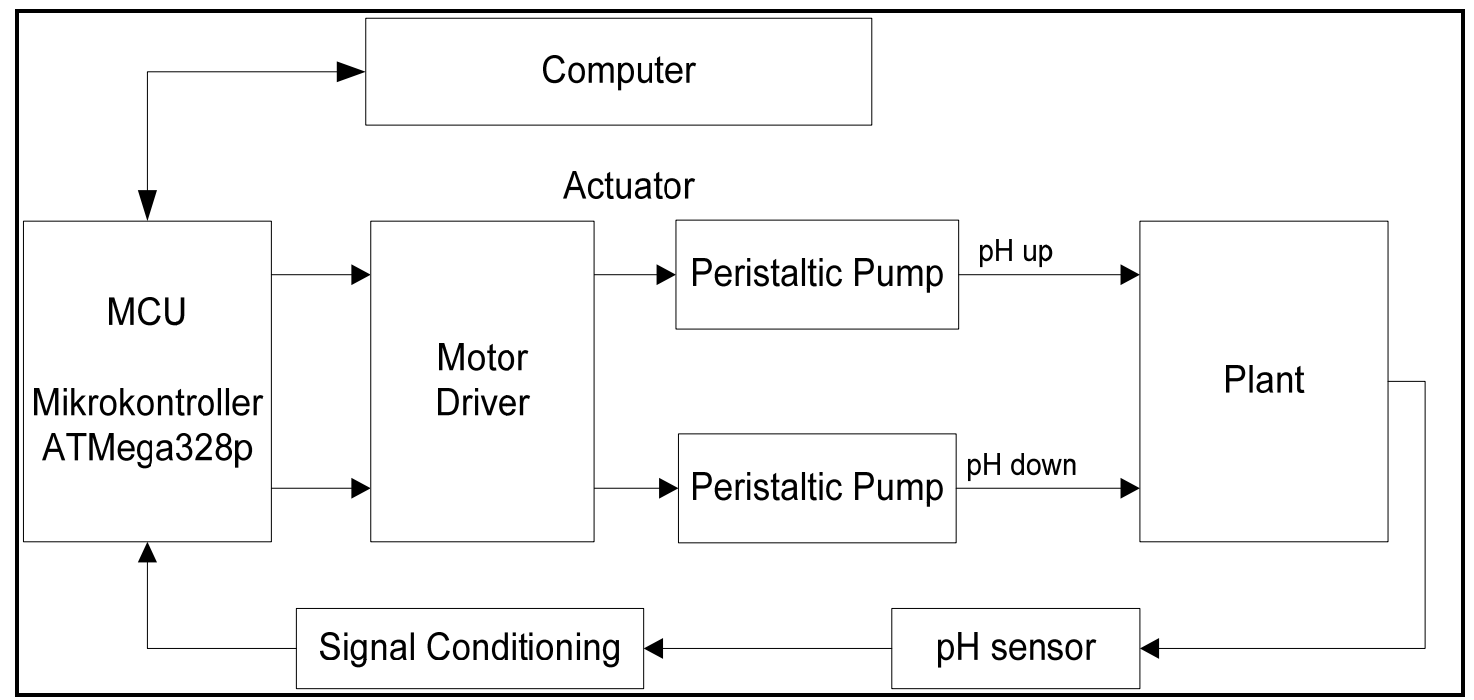

Gambar 1. Diagram Blok Sistem Pengendali PID

Sensor pH akan mengakusisi data dari pH larutan dalam plant. Data tersebut akan masuk ke dalam modul $\mathrm{pH}$ sebagai pengkondisi sinyal agar data dapat diterima oleh mikrokontroler. Mikrokontroler akan membaca data dari modul $\mathrm{pH}$ dan diolah menjadi besaran $\mathrm{pH}$. Setelah data diolah menjadi besaran $\mathrm{pH}$, mikrokontroler akan melakukan analisis untuk melakukan pengendalian terhadap $\mathrm{pH}$ yang hasilnya akan diberikan kepada aktuator (output unit). Aktuator tersebut akan memasukkan cairan $\mathrm{pH}$ up atau cairan $\mathrm{pH}$ down terhadap plant yang dipakai. Aktuator akan berkerja berdasarkan sinyal yang diberikan oleh mikrokontroler berdasarkan cara kerja pengendali PID. Data yang diperoleh mikrokontroler akan ditampilkan pada PC melalui serial monitor.

Sistem kendali $\mathrm{pH}$ larutan dirancang agar memungkinkan untuk melakukan pengendalian. Adapun spesifikasi sistem yang diimplementasikan yaitu:

1. Sensor $\mathrm{pH}$ khusus larutan dengan pembacaan 1-14 derajat keasaman.

2. Modul kendali berupa Arduino Uno dengan mikrokontroler ATmega328.

3. Nilai pH yang diatur sebesar 6,5 derajat keasaman.

4. Pemantauan secara realtime.

5. Modul driver motor $1298 \mathrm{n}$.

6. Motor peristaltik 12 volt maksimum dengan maksimum flow rate $100 \mathrm{ml} / \mathrm{menit}$.

7. Penampilan yang digunakan masih menggunakan PC melaui serial monitor.

8. Plant yang digunakan terdiri dari tangki yang diisi dengan $10 \mathrm{~L}$ larutan air, dimana larutan air tersebut akan diatur nilai pH nya.

\subsection{Perancangan dan Realisasi Perangkat Keras}

\subsubsection{Sensor pH dan Rangkaian Modul Pengkondisi sinyal}

Sensor pH yang digunakan merupakan buatan Dfrobot, terdiri dari tabung $\mathrm{pH}$ electrode yang terhubung dengan modul pengkondisi sinyal melalui konektor BNC. Pada perancangan sistem yang dibuat modul pengkondisi sinyal diberikan catu daya sebesar 5 v dari Arduino Uno. Bagian output modul tersebut dihubungkan pada pin A0 Arduino Uno. Gambar 2 menujukkan Sensor $\mathrm{pH}$ dan modul pengkondisi sinyal. 


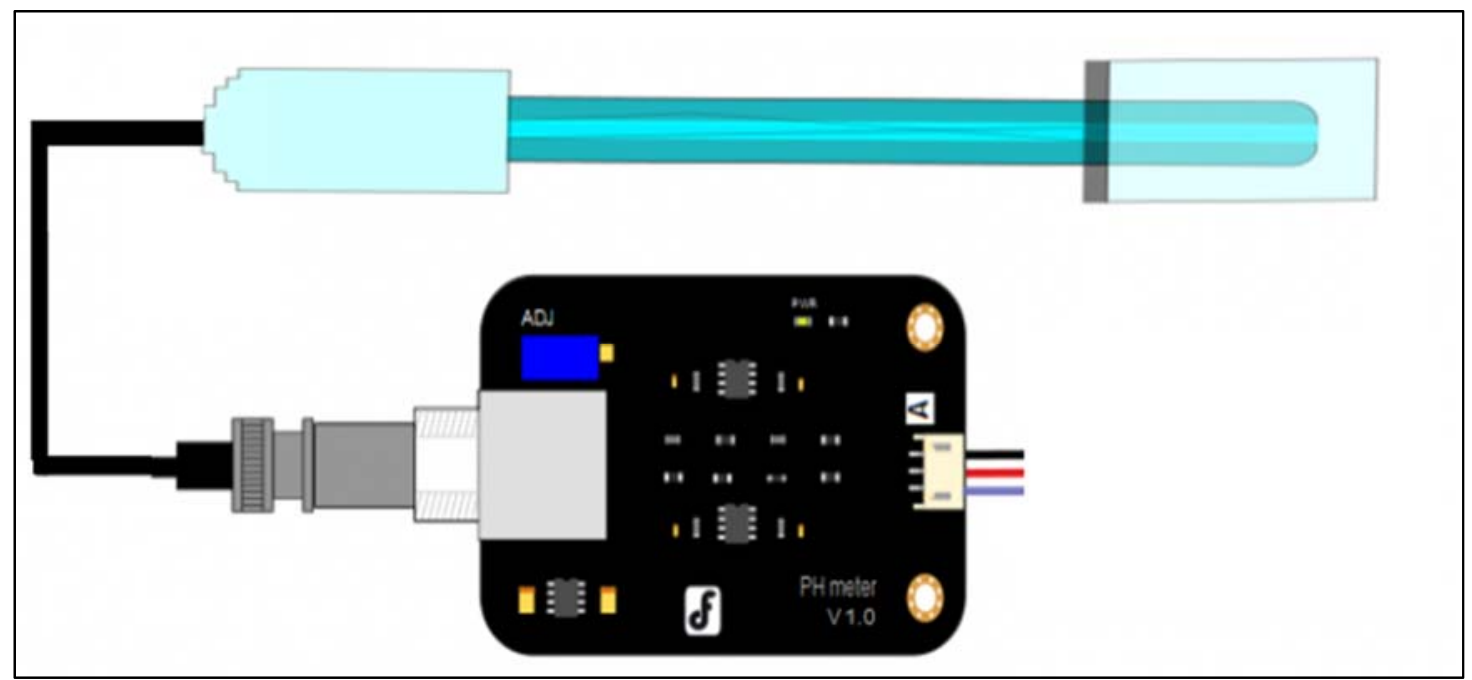

Gambar 2. Sensor pH dan Modul Pengkondisi Sinyal

Batas pengukuran sensor $\mathrm{pH}$ sebesar 0-14 derajat keasaman. Suhu kerja sensor adalah $0^{\circ} \mathrm{C}$ sampai $60^{\circ} \mathrm{C}$. Tingkat akurasi sensor sebesar $\pm 0,2 \mathrm{pH}\left(25^{\circ} \mathrm{C}\right)$. Modul pengkondisi sinyal terdiri dari dua rangkaian Op-amp. Rangkaian tersebut terdiri dari rangkaian non-inverting, dan rangkaian summing. Gambar 3 menunjukkan rangkaian singnal conditioning Sensor pH.

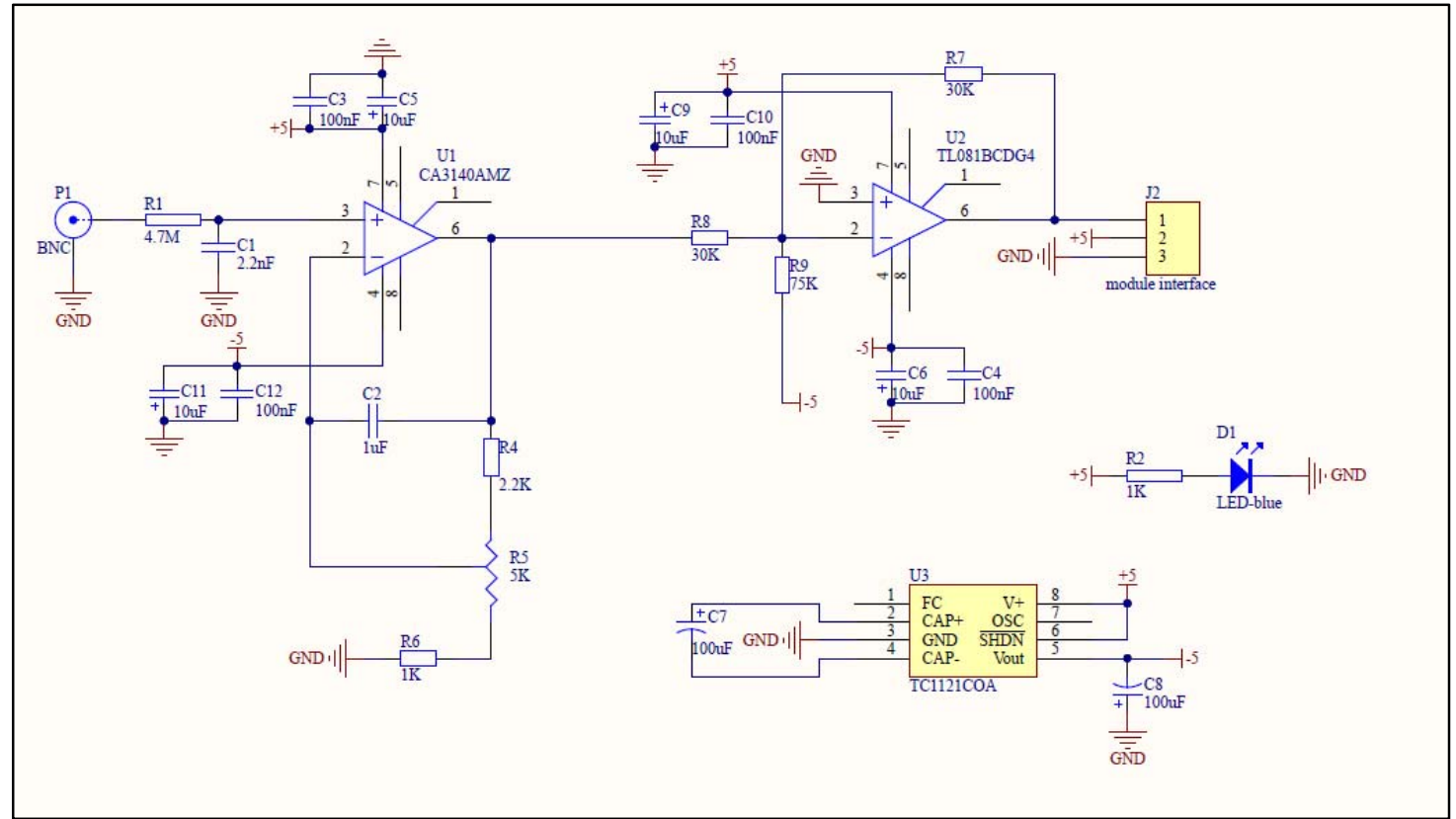

Gambar 3. Rangkaian Signal Conditioning Sensor pH (Industrial pH electrode, 2017)

Berdasarkan Gambar 3 tampak bahwa sensor pH menghasilkan keluaran berupa tegangan akan diolah pertama kali oleh rangkaian penguat non-inverting menggunakan IC CA3140AMZ. Rangkaian penguat pertama ini dilengkapi dengan Gain Adjustment Potentiometer dimana nilai pengali penguatan dapat diatur melalui potensiometer. Potensiometer ini digunakan ketika akan melakukan kalibrasi. Sinyal yang dihasilkan oleh penguat pertama sangat kecil, sehingga diolah kembali oleh rangkaian penguat kedua. Rangkaian penguat kedua yang digunakan merupakan rangkaian summing. Rangkaian ini menggunakan IC TL081BCDG4. Selanjutnya, modul sensor pH dilengkapi dengan rangkaian IC TC1121COA berfungsi sebagai pembalik 
tegangan dari tegangan catu daya. Tegangan ini digunakan sebagai catu daya kedua rangkaian penguat dan tegangan $-5 \mathrm{v}$ digunakan sebagai input penguat kedua.

\subsubsection{Arduino Uno}

Arduino Uno adalah sistem minimum yang berbasis mikrokontroler ATmega328. Perangkat ini dilengkapi rangkaian USB to serial converter, serta rangkaian catu daya sebesar $5 \mathrm{v}$ dan 3,3 v (Arduino, 2018). Arduino Uno akan digunakan sebagai unit kendali yang akan menerima data dari sensor dan melakukan pengendalian aktuator. Arduino Uno membutuhkan sumber daya sebesar 5 v yang diberikan dari Personal Computer.

\subsubsection{Driver Motor L298N}

Driver motor L298N digunakan pada sistem ini untuk mengatur kecepatan pompa peristaltik pada sistem pengendali menggunakan PID. Driver motor memiliki tegangan minimal power antara 5-35 v, arus masukan antara 0-36 mA, arus maksimal keluaran sebesar $2 \mathrm{~A}$, dan daya maksimum sebesar $25 \mathrm{~W}$. Driver motor diberikan catu daya sebesar 12 volt. Pin enA dan pin enB dihubungkan dengan pin output (pin 5 dan pin 6) PWM Arduino Uno. In1, in2, in3, dan in 4 dihubungkan dengan pin digital (3, 4, 8, dan 9) berfungsi untuk mengatur arah putaran pompa. Gambar 4 merupakan driver motor yang digunakan pada sistem pengendalian $\mathrm{pH}$.

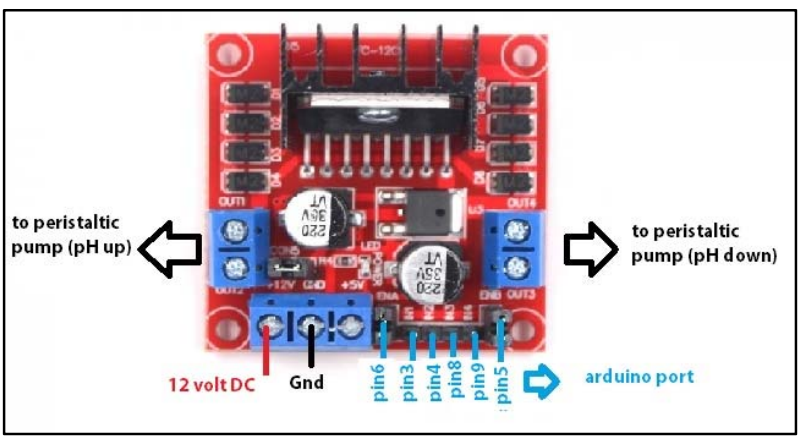

\section{Gambar 4. Driver Motor dengan Port yang Digunakan}

\subsubsection{Pompa Peristaltik}

Pompa peristaltik atau dosing pump digunakan untuk memasukkan cairan larutan ke dalam plant. Pada penelitian ini digunakan 2 buah pompa peristaltik, untuk mamasukan dua jenis cairan yaitu cairan $\mathrm{pH}$ up (kalium Hidroksida 10\%) dan $\mathrm{pH}$ down (Asam fosfat 10\%). Pada sistem pengendali PID pompa dikendalikan melalui driver motor L298N. Gambar 5 menunjukkan pompa peristaltik yang digunakan.

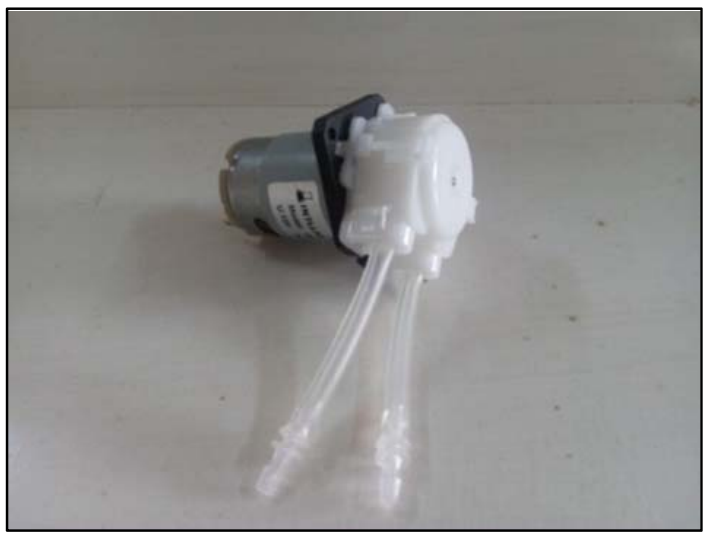

Gambar 5. Pompa Peristaltik 
Pompa peristaltik bekerja pada tegangan maksimal sebesar $12 \mathrm{v}$, daya motor maksimal $3 \mathrm{~W}$. Pompa peristaltik memiliki flow rate antara 0 sampai $100 \mathrm{ml} /$ menit, sedangkan suhu kerja pompa antara $0^{\circ} \mathrm{C}$ sampai $40^{\circ} \mathrm{C}$.

\subsection{Perancangan dan Realisasi Perangkat Lunak}

Perangkat lunak yang dirancang menggunakan bahasa pemograman $\mathrm{C}$ melalui aplikasi IDE (Integrated development enviroment) dari Arduino. Secara umum terdapat 5 (lima) proses komputasi yang dilakukan pada sistem ini. Proses-proses tersebut adalah inisialisasi parameter, menghitung nilai ADC, konversi nilai $A D C$ ke tegangan dan nilai $\mathrm{pH}$, aksi kendali, dan penampilan data. Gambar 6 merupakan diagram alir secara umum dari keseluruhan sistem. Gambar 6 menunjukkan diagram alir program utama kendali PID.

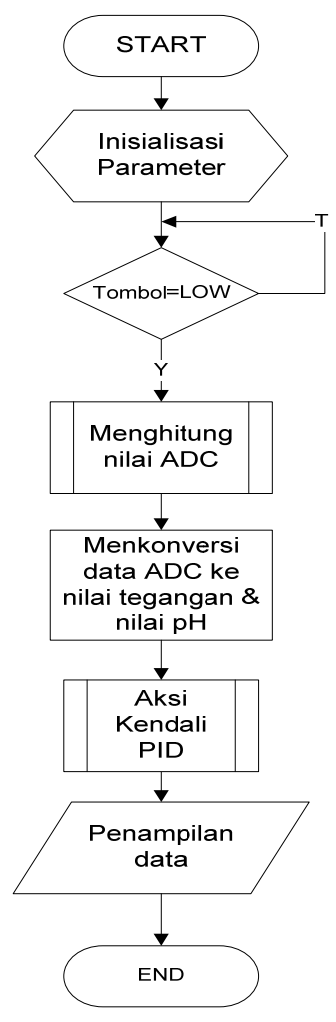

\section{Gambar 6. Diagram Alir Program Utama Kendali PID}

Berdasarkan Gambar 6 tahap pertama dari program adalah melakukan insialisasi parameter yang digunakan dalam program utama, diantaranya parameter integer, float, include library untuk kendali PID, dan define value. Sebelum proses pengendalian dimulai sistem akan menunggu proses penekanan "Tombol". Setelah "Tombol" selesai ditekan maka proses pengendalian akan berkerja. Pada tahap selanjutnya program akan menghitung nilai ADC dengan cara mengambil 20 sample data ADC, kemudian data-data tersebut akan diurutkan dari nilai terkecil sampai terbesar. Selanjutnya, mengambil sample tengah dari data yang sudah diurutkan yaitu data urutan ke-6 sampai data urutan ke-15. Terakhir program akan mengambil nilai rata-rata nilai ADC tersebut. Setelah menyelesaikan tahap menghitung nilai $A D C$ yaitu program akan mengonversi nilai $A D C$ ke dalam bentuk $\mathrm{pH}$ dan tegangan.

Tahap aksi kendali PID yang diimplementasikan pada mikrokontroler harus diubah ke dalam persamaan diskret. Aksi kendali PID dari pengendali Propotional, pengendali Integral, dan pengendali Derivative menggunakan Persamaan (1). 


$$
\begin{aligned}
& u(t)=K p e(t)+k i \int_{0}^{t} e(t) d t+K d \frac{d e(t)}{d t} \\
& e(t)=\text { setpoint }- \text { input }(\text { data } A D C) \\
& u(n)=K p e(n)
\end{aligned}
$$

Dengan $\mathrm{u}(\mathrm{t})$ adalah sinyal kendali, dimana sinyal tersebut akan mengendalikan output pengendali. e(t) adalah nilai kesalahan (error). Nilai input didapat dari hasil pembacaan sensor $\mathrm{pH}$. Kp adalah konstanta propotional, Ki adalah konstanta integral, dan Kd adalah konstanta derivative. Pada Persamaan (1) merupakan persamaan kawasan waktu kontinu (analog). Sedangkan agar persamaan tersebut dapat direalisasikan dalam bentuk program, maka persamaan diubah ke dalam persamaan diskret. Persamaan (3) merupakan persamaan diskret pada pengendali propotional. Berdasarkan Persamaan (3) nilai Kp akan terus dikalikan dengan dengan nilai error pada setiap sample data yang diambil. Nilai $\mathrm{n}$ merupakan sebuah notasi yang menunjukkan pengambilan data pada waktu-waktu tertentu. Persamaan (4), (5), dan (6) merupakan persamaan diskret pada pengendali integral.

$$
\begin{aligned}
& u(n)=K i \sum_{i=0}^{n} e(i) T s \\
& u(n)=\operatorname{KiTs}[e(0)+e(1)+\cdots+e(n-1)+e(n)] \\
& u(n)=\operatorname{KiTs}[e(n-1)+e(n)]
\end{aligned}
$$

Notasi Ts merupakan waktu sampling. Integral adalah suatu operator matematis dalam kawasan kontinu jika diubah ke dalam bentuk diskret akan menjadi sigma $(\Sigma)$, yang merupakan operator matematis kawasan diskret. Fungsi dari operator sigma adalah menjumlahkan nilai ke-i sampai nilai ke-n. Berdasarkan Persamaan (6) nilai error sebelumnya akan dijumlahkan dengan nilai error-error sebelumnya hingga nilai error sekarang. Hasil penjumlahan error tersebut akan dikalikan dengan nilai Ki dan nilai Ts. Pengendali derivative didapat berdasarkan laju perubahan sinyal error Persamaan (7).

$$
\frac{d e(t)}{d t}=\frac{d \operatorname{Setpoint}(t)}{d t}-\frac{d \operatorname{input}(t)}{d t}
$$

Karena setpoint bernilai konstan, maka:

$$
\begin{aligned}
& \frac{d e(t)}{d t}=-\frac{d \operatorname{input}(t)}{d t} \\
& u(t)=K d \frac{d e(t)}{d t}=-K d \frac{d \text { input }(t)}{d t} \\
& u(n)=-K d \frac{\operatorname{input}(n)-\operatorname{input}(n-1)}{T s}
\end{aligned}
$$

Dari Persamaan (9) kontinu diubah menjadi persaman diskret seperti pada persamaan (10). Persamaan derivative adalah suatu operator matematis dalam kawasan kontinu jika diubah menjadi persamaan diskret maka akan menjadi limit. Dimana fungsi operator limit adalah mengurangi nilai ke-n dengan nilai ke n-1. Berdasarkan Persamaan (10) hasil perhitungan derivative adalah nilai negatif dari hasil pengurangan nilai input dengan nilai inputsebelumnya, dan dikalikan dengan $\mathrm{Kd} / \mathrm{Ts}$. 
Analisis Penerapan Kendali Otomatis Berbasis PID Terhadap pH Larutan Nutrisi Tanaman Hidroponik

\section{HASIL PENELITIAN DAN ANALISIS}

Pengujian dilakukan terhadap pengujian sub-sistem dan pengujian sistem terintegrasi. Pengujian sub-sistem meliputi pengujian sensor $\mathrm{pH}$ dan pengujian aktuator, sedangkan pengujian sistem terintegrasi meliputi pengujian pengendali Propotional $(P)$, pengendali Propotional-Integral(PI), dan pengendali Propotional-Integral-Derivative (PID).

\subsection{Pengujian Sub-Sistem}

Pengujian sub-sistem dilakukan untuk melihat respon dan karakteristik sensor dan aktuator berdasarkan parameter yang diperlukan.

\subsubsection{Pengujian Sensor pH}

Pengujian Sensor pH dilakukan di dalam wadah berisi $500 \mathrm{ml}$ air dengan suhu $28^{\circ} \mathrm{C}$. Di dalam air tersebut $\mathrm{pH}$ akan diatur dari 2-13 derajat keasaman. Data yang diambil dalam pengujian ini berupa nilai output tegangan setiap kenaikan derajat keasaman dan data perbandingan nilai $\mathrm{pH}$ yang terbaca oleh mikrokontoler dengan nilai acuan. Nilai acuan didapat dari hasil pembacaan $\mathrm{pH}$ meter digital. Hasil pengujian sensor pH dapat dilihat melalui Tabel 1. Data pengujian sensor diperoleh melalui fitur serial print dari aplikasi Arduino IDE.

Tabel 1. Pengujian Sub-sistem Sensor pH

\begin{tabular}{|c|c|c|c|c|c|c|c|c|c|c|c|c|}
\hline \multirow{2}{*}{$\begin{array}{c}\mathrm{pH} \\
\text { meter }\end{array}$} & \multicolumn{3}{|c|}{ percobaan 1} & \multicolumn{3}{|c|}{ percobaan 2} & \multicolumn{3}{|c|}{ percobaan 3} & \multicolumn{3}{|c|}{ percobaan 4} \\
\hline & Output(V) & nilai $\mathrm{pH}$ & $\Delta \mathrm{pH}$ & Output(V) & nilai pH & $\Delta \mathrm{pH}$ & Output(V) & nilai $\mathrm{pH}$ & $\Delta \mathrm{pH}$ & Output(V) & nilai $\mathrm{pH}$ & $\Delta \mathrm{pH}$ \\
\hline 2 & 0,69 & 1,92 & $-0,08$ & 0,69 & 1,92 & $-0,08$ & 0,71 & 2,01 & 0,01 & 0,71 & 2,01 & 0,01 \\
\hline 2,5 & 0,82 & 2,45 & $-0,05$ & 0,79 & 2,34 & $-0,16$ & 0,82 & 2,46 & $-0,04$ & 0,83 & 2,52 & 0,02 \\
\hline 3 & 0,94 & 2,98 & $-0,02$ & 0,91 & 2,85 & $-0,15$ & 0,94 & 2,97 & $-0,03$ & 0,95 & 3,03 & 0,03 \\
\hline 3,5 & 1,07 & 3,51 & 0,01 & 1,04 & 3,39 & $-0,11$ & 1,06 & 3,49 & $-0,01$ & 1,08 & 3,55 & 0,05 \\
\hline 4 & 1,19 & 4,02 & 0,02 & 1,17 & 3,94 & $-0,06$ & 1,18 & 4 & 0 & 1,19 & 4,05 & 0,05 \\
\hline 4,5 & 1,32 & 4,55 & 0,05 & 1,28 & 4,4 & $-0,1$ & 1,31 & 4,52 & 0,02 & 1,32 & 4,55 & 0,05 \\
\hline 5 & 1,44 & 5,07 & 0,07 & 1,4 & 4,91 & $-0,09$ & 1,43 & 5,03 & 0,03 & 1,44 & 5,07 & 0,07 \\
\hline 5,5 & 1,56 & 5,57 & 0,07 & 1,53 & 5,43 & $-0,07$ & 1,55 & 5,54 & 0,04 & 1,55 & 5,55 & 0,05 \\
\hline 6 & 1,67 & 6,06 & 0,06 & 1,64 & 5,94 & $-0,06$ & 1,67 & 6,04 & 0,04 & 1,68 & 6,08 & 0,08 \\
\hline 6,5 & 1,8 & 6,58 & 0,08 & 1,77 & 6,45 & $-0,05$ & 1,79 & 6,54 & 0,04 & 1,8 & 6,58 & 0,08 \\
\hline 7 & 1,91 & 7,08 & 0,08 & 1,89 & 6,98 & $-0,02$ & 1,91 & 7,07 & 0,07 & 1,92 & 7,09 & 0,09 \\
\hline 7,5 & 2,02 & 7,53 & 0,03 & 2,04 & 7,59 & 0,09 & 2,01 & 7,5 & 0 & 2,03 & 7,59 & 0,09 \\
\hline 8 & 2,14 & 8,04 & 0,04 & 2,15 & 8,08 & 0,08 & 2,13 & 8,01 & 0,01 & 2,16 & 8,1 & 0,1 \\
\hline 8,5 & 2,26 & 8,55 & 0,05 & 2,27 & 8,59 & 0,09 & 2,26 & 8,53 & 0,03 & 2,28 & 8,62 & 0,12 \\
\hline 9 & 2,38 & 9,06 & 0,06 & 2,39 & 9,08 & 0,08 & 2,38 & 9,05 & 0,05 & 2,4 & 9,11 & 0,11 \\
\hline 9,5 & 2,5 & 9,56 & 0,06 & 2,51 & 9,57 & 0,07 & 2,5 & 9,57 & 0,07 & 2,52 & 9,63 & 0,13 \\
\hline 10 & 2,62 & 10,06 & 0,06 & 2,62 & 10,07 & 0,07 & 2,63 & 10,09 & 0,09 & 2,64 & 10,12 & 0,12 \\
\hline 10,5 & 2,74 & 10,56 & 0,06 & 2,74 & 10,58 & 0,08 & 2,75 & 10,61 & 0,11 & 2,76 & 10,63 & 0,13 \\
\hline 11 & 2,86 & 11,07 & 0,07 & 2,86 & 11,06 & 0,06 & 2,87 & 11,13 & 0,13 & 2,87 & 11,12 & 0,12 \\
\hline 11,5 & 2,97 & 11,56 & 0,06 & 2,97 & 11,55 & 0,05 & 3 & 11,65 & 0,15 & 2,99 & 11,64 & 0,14 \\
\hline 12 & 3,09 & 12,06 & 0,06 & 3,09 & 12,03 & 0,03 & 3,12 & 12,17 & 0,17 & 3,11 & 12,14 & 0,14 \\
\hline 12,5 & 3,21 & 12,55 & 0,05 & 3,2 & 12,52 & 0,02 & 3,24 & 12,69 & 0,19 & 3,23 & 12,63 & 0,13 \\
\hline 13 & 3,32 & 13,02 & 0,02 & 3,32 & 13,04 & 0,04 & 3,36 & 13,19 & 0,19 & 3,36 & 13,19 & 0,19 \\
\hline
\end{tabular}

Tabel 1 menunjukkan selisih yang didapat dari hasil pengukuran berkisar diantara range $-0,11$ $\mathrm{pH}$ sampai $0,19 \mathrm{pH}$, data tersebut menunjukkan sensor $\mathrm{pH}$ yang digunakan sesuai dengan spesifikasi akurasi, yaitu sebesar $\pm 0,20 \mathrm{pH}$. Gambar 7 menunjukkan hubungan $\mathrm{pH}$ terhadap nilai tegangan. 


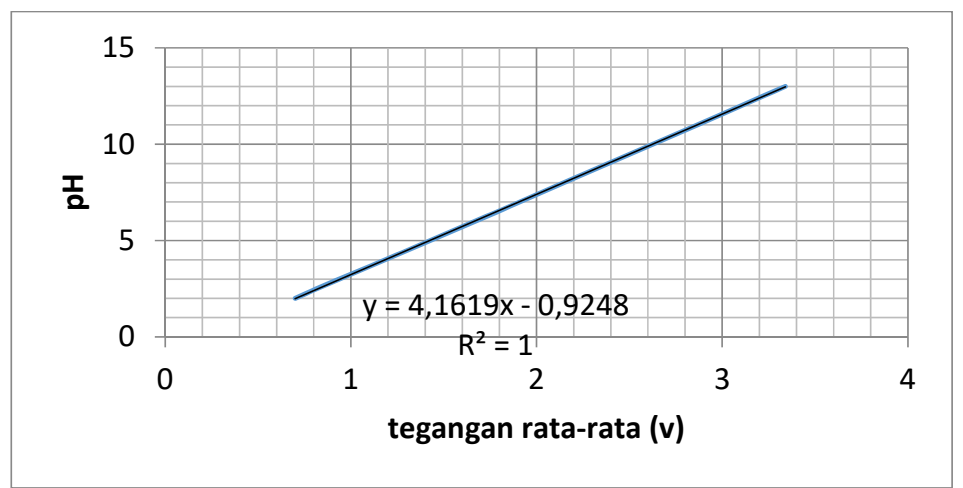

Gambar 7. Grafik Hubungan pH terhadap Tegangan

Gambar 8 menunjukkan bahwa hubungan antara pH terhadap nilai tegangan outputmodul pH memiliki kelinieran yang baik, sehingga dapat disimpulkan kondisi modul $\mathrm{pH}$ masih layak untuk dipakai. Persamanan yang didapat dari Gambar 7 akan digunakan dalam program untuk mengonversi nilai tegangan ke dalam nilai $\mathrm{pH}$.

\subsubsection{Pengujian Pompa Peristaltik}

Pengujian ini dilakukan untuk mengetahui karakteristik pompa yang digunakan. Pada proses pengujian input yang digunakan berupa nilai PWM. Pengujian dilakukan dengan mengihitung waktu yang dibutuhkan untuk mengisi $100 \mathrm{ml}$ air pada gelas ukur menggunakan stopwatch. Tabel 2 dan Gambar 8 menunjukkan data hasil pengukuran yang telah dilakukan.

Tabel 2. Hasil Pengujian Pompa dengan PWM

\begin{tabular}{|c|c|c|c|c|c|c|c|c|}
\hline \multirow{2}{*}{ PWM } & \multicolumn{4}{|c|}{$\mathrm{pH}$ down } & \multicolumn{4}{|c|}{$\mathrm{pH}$ up } \\
\hline & tegangan $(v)$ & pompa & flow (ml/menit) & waktu (menit) & tegangan $(\mathrm{v})$ & pompa & flow (ml/menit) & waktu (menit) \\
\hline 30 & 0,25 & off & - & - & 0,25 & off & - & - \\
\hline 55 & 0,681 & off & - & - & 0,65 & off & $=-$ & - \\
\hline 80 & 1,176 & off & - & - & 1,16 & off & - & - \\
\hline 105 & 1,86 & off & - & - & 1,83 & off & - & - \\
\hline 130 & 4,7 & on & 28,57 & 3,5 & 4,9 & on & 35,97 & 2,78 \\
\hline 155 & 6,25 & on & 46,51 & 2,15 & 6,56 & on & 54,05 & 1,85 \\
\hline 180 & 7,45 & on & 56,18 & 1,78 & 7,63 & on & 63,29 & 1,58 \\
\hline 205 & 8,22 & on & 67,57 & 1,48 & 8,44 & on & 76,34 & 1,31 \\
\hline 230 & 9,05 & on & 75,19 & 1,33 & 9,18 & on & 81,30 & 1,23 \\
\hline 255 & 10,67 & on & 86,21 & 1,16 & 10,7 & on & 95,24 & 1,05 \\
\hline
\end{tabular}

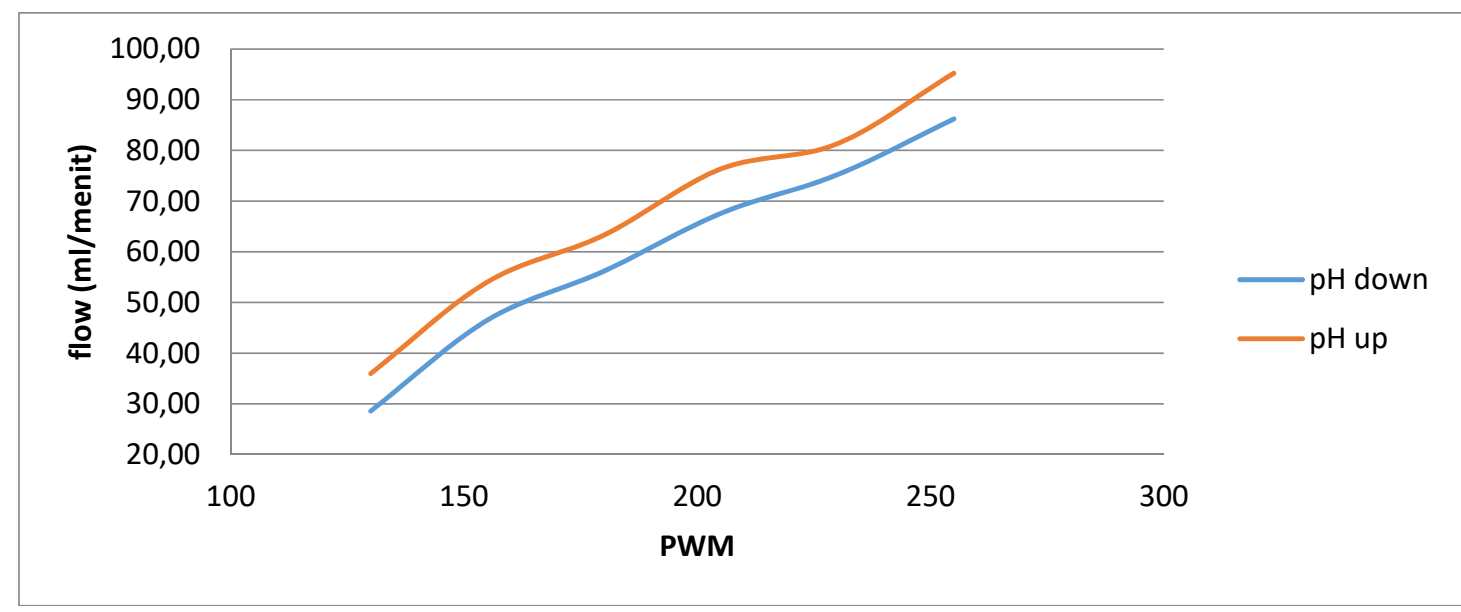

Gambar 8. Grafik Flow terhadap PWM 
Berdasarkan Tabel 2 dan Gambar 8 didapatkan hasil dari masing-masing pengujian menunjukkan karakteristik pompa peristaltik yang digunakan pada $\mathrm{pH}$ up memiliki kemampuan mengalirkan cairan sedikit lebih cepat dibandingkan dengan pompa peristaltik yang digunakan pada $\mathrm{pH}$ down. Tabel 2 menunjukkan pompa peristaltik berkerja ketika nilai PWM yang diberikan mulai dari 130 pada masing-masing pompa.

\subsection{Pengujian Sistem Terintegrasi}

Pengujian sistem terintegrasi merupakan pengujian keseluruhan sistem untuk melihat hasil respon sistem. Pengujian ini dilakukan dengan memasukkan nilai $\mathrm{pH}$ yang diinginkan, yaitu sebesar 6,5 derajat keasaman. Nilai tersebut merupakan nilai tengah dari batas pH yang dibutuhkan dan nilai tersebut dapat mewakili kebutuhan banyak jenis tanaman. Pengujian dilakukan di dalam ruangan dengan suhu ruangan sebesar $30,2^{\circ} \mathrm{C}$ dan kelembaban sebesar $52 \%$. Pengendalian dilakukan pada plant yang terdiri dari tangki yang berisi air sebesar $10 \mathrm{~L}$. Di dalam plant tersedia pompa yang berfungsi sebagai pengaduk larutan. Sensor dikalibrasi setiap pengujian dilakukan. Gambar 9 menunjukkan plant yang digunakan pada sistem.

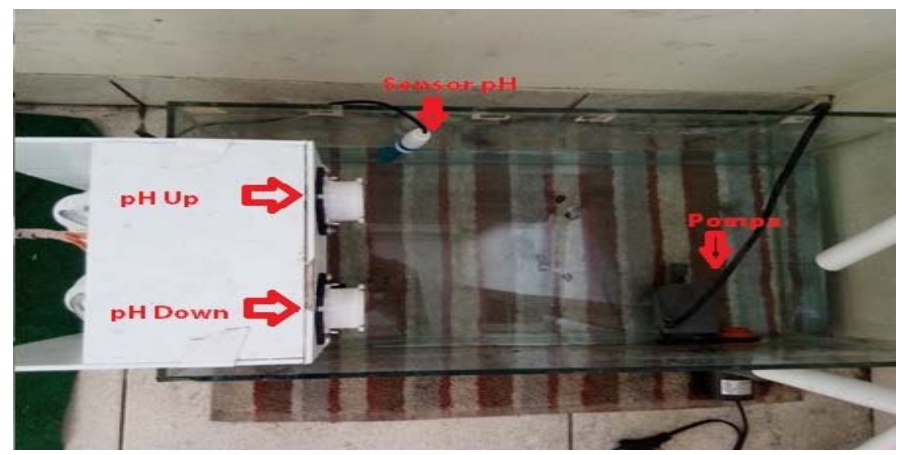

Gambar 9. Plant yang digunakan pada Sistem

\subsubsection{Pengujian Pengendali Propotional(P)}

Pengujian dilakukan dengan mengatur kondisi awal plant pada nilai 4 derajat keasaman, kemudian pengendali diaktifkan dan data diambil melalui aplikasi PLX-DAQ. Pengujian ini diharapkan dapat mengurangi error steady state. Menentukan nilai paramater $\mathrm{P}$ adalah dengan metode trial and error. Pengujian dilakukan sebanyak 2 kali dengan nilai $\mathrm{Kp}=0,1$ dan $\mathrm{Kp}=1$. Berikut hasil pengujian pengendali Propotional.

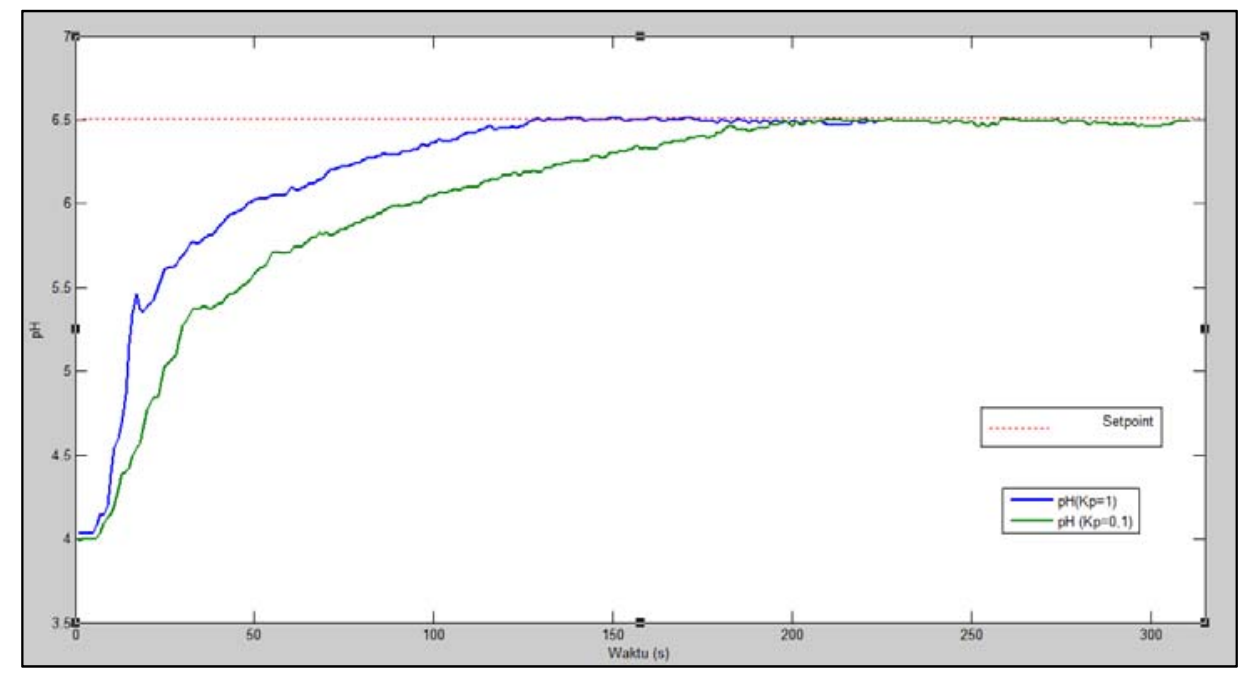

Gambar 10. Grafik Respon Pengendali Propotional(P) 
Gambar 10 menunjukkan pada saat nilai $\mathrm{Kp}=1$ (grafik berwarna biru) waktu rise time jauh lebih sedikit dibandingkan dengan nilai $\mathrm{Kp}=0,1$ (grafik berwarna hijau). Namun, masingmasing pengendali dapat menghilangkan overshoot dan nilai error steady state hampir tidak terlihat. Sistem setimbang saat nilai $\mathrm{Kp}=1$ yaitu pada waktu 126 detik, sedangkan saat nilai $\mathrm{Kp}=0,1$ sistem setimbang pada waktu 194 detik. Nilai Kp yang besar dapat memperkecil rise time.

\subsubsection{Pengujian Pengendali Propotional-Integral(PI)}

Pengujian Pengendali PI dilakukan sebanyak 3 kali. Pengujian dilakukan dengan mengatur kondisi awal plant pada nilai 4 derajat keasaman, kemudian pengendali diaktifkan dan data diambil melalui aplikasi PLX-DAQ. Menentukan nilai paramater $\mathrm{P}$ dan parameter I adalah dengan metode trial and error. Pengujian pertama nilai yang digunakan adalah $\mathrm{Kp}=0,45$, $\mathrm{Ki}=0,3$ (grafik berwarna biru), pengujian kedua nilai yang digunakan adalah $\mathrm{Kp}=0,45, \mathrm{Ki}=0,2$ (grafik berwarna hijau), dan pengujian ketiga nilai yang digunakan adalah $\mathrm{Kp}=0,45, \mathrm{Ki}=0,01$ (grafik berwarna merah). Hasil pengujian dapat dilihat pada Gambar 11.

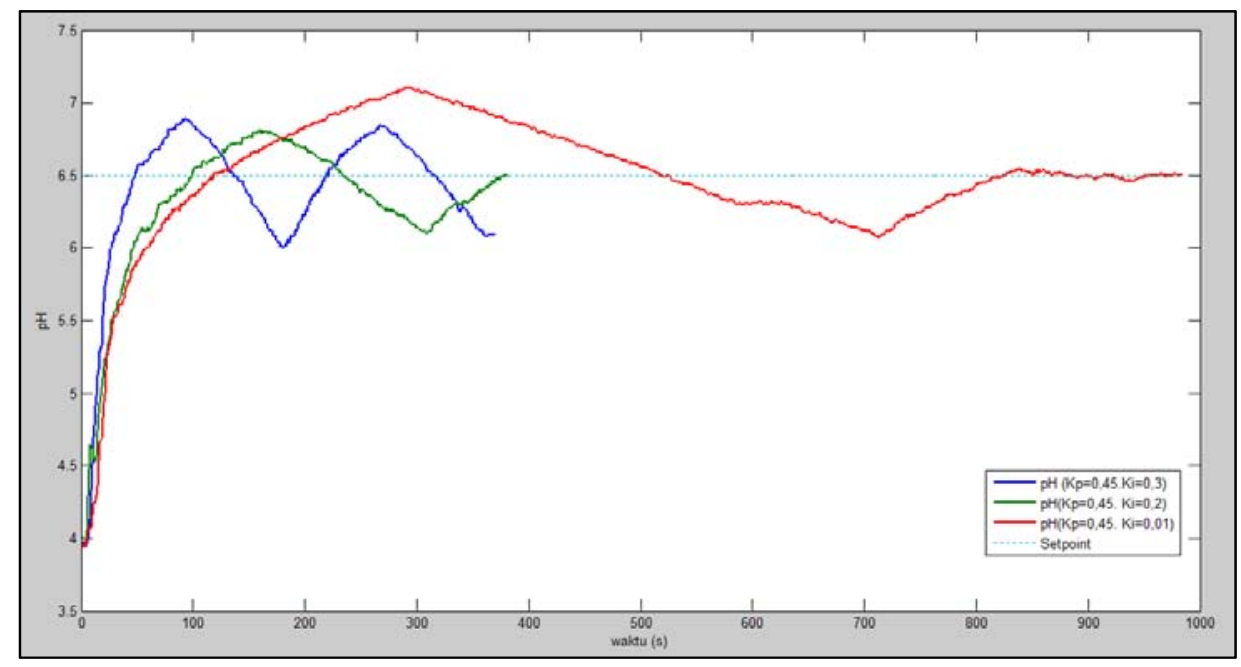

Gambar 11. Grafik Respon Pengendali Propotional-Integral(PI)

Berdasarkan Gambar 11 pengujian pertama dan kedua respon sistem masih berosilasi. Pengujian ketiga (grafik berwarna merah) menunjukkan bahwa sistem stabil pada waktu 828 detik, namun masih ada sedikit osilasi dan menghasilkan overshoot dan undershoot. Berdasarkan grafik tersebut dengan menurunkan nilai Ki dapat menghilangkan osilasi sistem, namun dapat memperlambat respon sistem.

\subsubsection{Pengujian Pengendali Propotional-Integral-Derivative (PID)}

Pengujian Pengendali PID dilakukan sebanyak 3 kali. Pengujian dilakukan dengan mengatur kondisi awal plant pada nilai 4 derajat keasaman, kemudian pengendali diaktifkan dan data diambil melalui aplikasi PLX-DAQ. Menentukan nilai paramater $\mathrm{P}$ dan parameter I adalah dengan metode trial and error. Pengujian pertama nilai yang digunakan adalah $\mathrm{Kp}=0,6$, $\mathrm{Ki}=0,6, \mathrm{Kd}=0,016$ (grafik berwarna biru), pengujian kedua nilai yang digunakan adalah $\mathrm{Kp}=0,6, \mathrm{Ki}=0,2, \mathrm{Kd}=0,3$ (grafik berwarna hijau), dan pengujian ketiga nilai yang digunakan adalah $\mathrm{Kp}=0,6, \mathrm{Ki}=0,01, \mathrm{Kd}=0,2$ (grafik berwarna merah). Dengan menambahkan pengendali derivative dapat meningkatkan kestabilan sistem. Hasil pengujian dapat dilihat pada Gambar 12. 


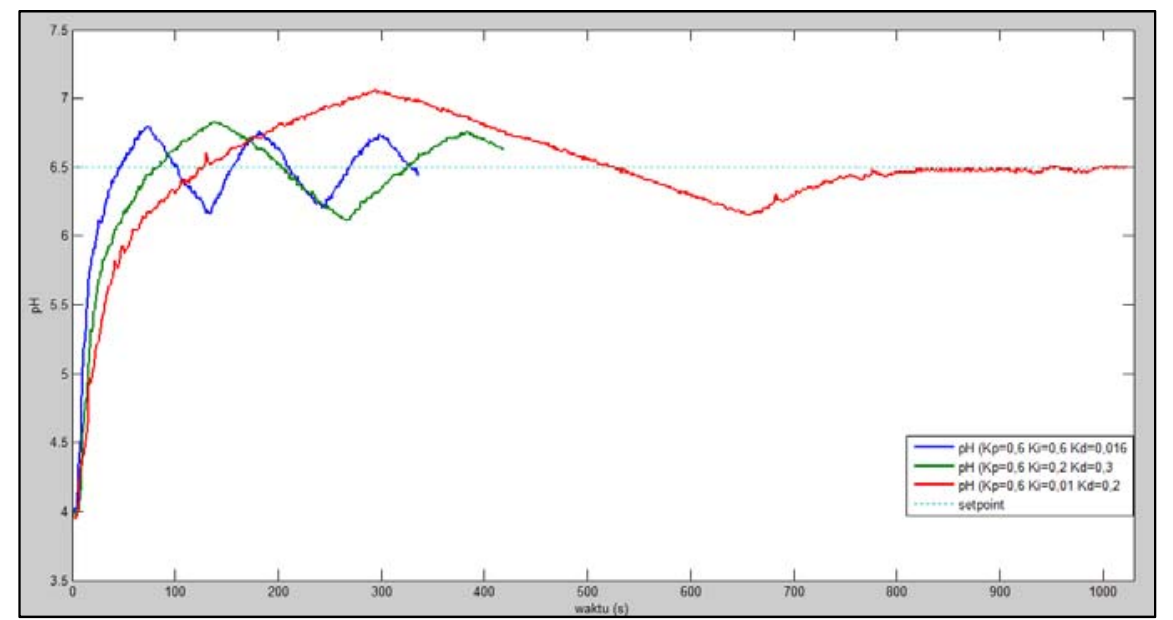

Gambar 12. Grafik Respon Pengendali Propotional-Integral-Derivative (PID)

Berdasarkan Gambar 12 hasil pengujian pertama dan kedua respon sistem masih bersosilasi. Pengujian ketiga (grafik berwarna merah) menunjukkan sistem stabil pada waktu 800 detik, tetapi sistem terdapat overshoot dan undershoot. Hal tersebut bisa disebabkan nilai konstanta derivative yang diberikan kurang besar. Sifat dari kendali derivative dapat mengurangi overshoot pada respon sistem.

Setelah melakukan pengujian, data terbaik dari masing-masing pengendali dibandingkan untuk melihat perbedaan karakteristik dari setiap pengendali yang digunakan pada penelitian ini. Berikut Gambar 13 merupakan grafik perbandingan hasil pengujian dari masing-masing pengendali.

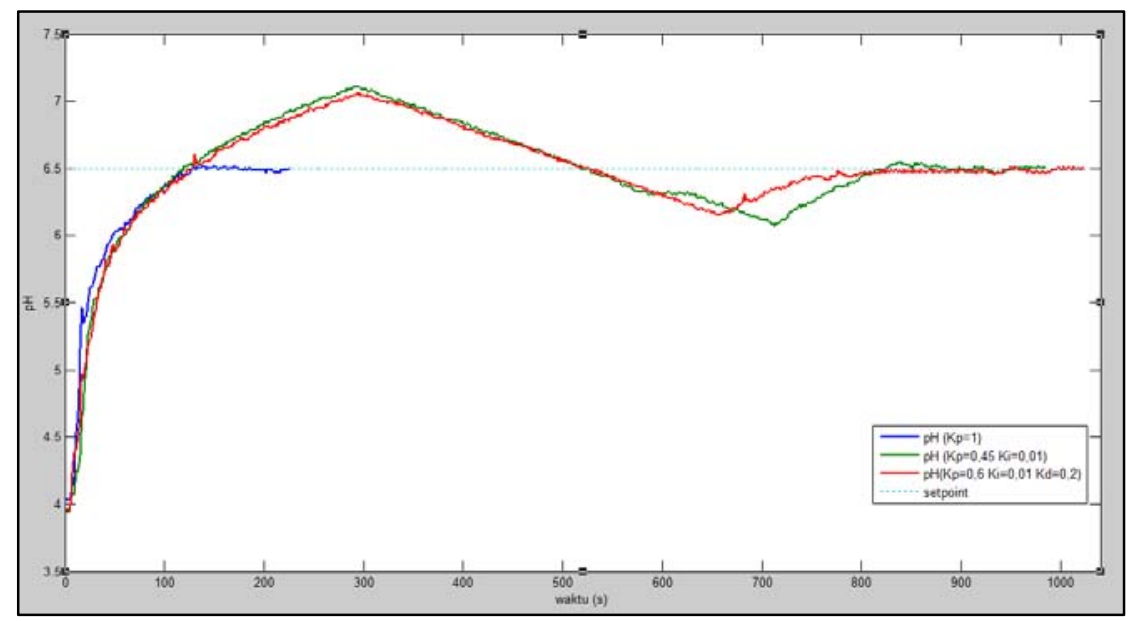

Gambar 13. Grafik Perbandingan Masing-masing Pengendali

Berdasarkan Gambar 13 sistem dengan menggunakan pengendali Propotional memiliki respon lebih baik dibandingkan dengan pengendali lainnya, dilihat dari pengendali Propotional tidak memiliki overshoot maupun undershoot. Sistem mencapai kesetimbangan pada pengendali propotiona/dikisaran waktu 126 detik. Waktu yang dibutuhkan untuk mencapai kesetimbangan pada pengendali $\mathrm{P}$ lebih cepat dibandingkan dengan pengendali PI dan PID.

Apabila ditinjau dari larutan yang digunakan untuk mengendalikan $\mathrm{pH}$, pengendali PI dan PID mengeluarkan volume larutan $\mathrm{pH}$ up atau larutan $\mathrm{pH}$ down lebih banyak. Karena, respon sistem sebelum mencapai stabil terdapat overshoot dan undershoot, serta respon sistem yang terbilang lama. Pada dasarnya pengendali menggunakan metode Propotional, Propotional- 
Hadiatna, dkk

Integral, maupun Propotional-Integral-Derivative mampu menjaga sistem berada tepat pada nilai setpoint-nya. Namun, untuk menjaga sistem agar terus mendekati nilai setpoint sistem pengendali akan terus merespon setiap perubahan sistem. Sehingga, larutan yang digunakan untuk mengendalikan sistem akan lebih banyak.

\section{KESIMPULAN}

Berdasarkan hasil pengujian penerapan sistem pengendali PID terhadap larutan, dapat diambil beberapa kesimpulan sebagai berikut:

1. Pengendali P, PI, dan PID dapat diterapkan untuk mengendalikan $\mathrm{pH}$ tanaman, namun memiliki beberapa kekurangan seperti membutuhkan lebih banyak larutan $\mathrm{pH}$ up dan larutan $\mathrm{pH}$ down untuk menjaga kesetimbangan sistem. Dari ketiga jenis pengendali, pengendali $\mathrm{P}$ mampu mengendalikan $\mathrm{pH}$ larutan lebih baik dibandingkan dengan pengendali PI dan PID.

2. Nilai $\mathrm{Kp}, \mathrm{Ki}$, dan $\mathrm{Kd}$ yang didapat dengan menggunakan metode tunning trial and error yaitu $\mathrm{Kp}=1$ untuk pengendali Propotional $(\mathrm{P}), \mathrm{Kp}=0,45 \mathrm{Ki}=0,01$ untuk pengendali Propotional-Integral (PI), dan $\mathrm{Kp}=0,6 \mathrm{Ki}=0,01 \mathrm{Kd}=0,2$ untuk pengendali PropotionalIntegral-Derivative (PID). Nilai masing-masing konstanta dapat dari hasil uji coba trial and error.

3. Berdasarkan data pengujian sistem pengendali PID. Waktu yang dibutuhkan agar sistem stabil dinilai setpoint dikisaran 126 detik pada pengendali Protional (P), sedangkan pada pengendali Propotional-Integral (PI) waktu yang didapat berkisar 828 detik, dan pada pengendali Propotional-Integral-Derivative (PID) waktu yang didapat berkisar 800 detik.

4. Pengendali Propotional menghasilkan grafik respon lebih baik dibandingkan dengan pengendali Propotional-Integra/dan Propotional-Integral-Derivative untuk mengendalikan $\mathrm{pH}$ larutan, tetapi pada pengendai Propotional nilai error tidak dapat dihilangkan sepenuhnya, sehingga akan selalu mengeluarkan larutan $\mathrm{pH}$ up dan $\mathrm{pH}$ down. Hal tersebut dapat meyebabkan pemborosan larutan $\mathrm{pH}$ up dan $\mathrm{pH}$ down

\section{DAFTAR RUJUKAN}

Arduino. (2018). Arduino Uno. Dipetik Agustus 20, 2018, dari Arduino https://store.arduino.cc/usa/arduino-uno-rev3

Bingi, K., Ibrahim, R., Karsiti, M.N., Chung, T.D., \& Hassan, S.M. (2016). Optimal PID Control of $\mathrm{pH}$ Neutralization Plant. $2^{\text {nd }}$ IEEE International Symposium on Robotics and Manufacturing Automation (ROMA).

Industrial pH electrode (SKU:FIT0348). (2017). Dipetik Desember, 2017, dari www.dfrobot.com/wiki/index.php/Industrial_pH_electrode(SKU:FIT0348).

Lee, S., \& Lee, J. (2015). Beneficial Bacteria and Fungi in Hydroponic Systems: Types and Characteristics of Hydroponic Food Production Methods. Scientia Horticulturae, 195, $206-215$.

Mitalom. (2018). Pengaruh pH Larutan Nutrisi pada Tanaman Hidroponik. Dipetik Juli 13, 2018. https://mitalom.com/pengaruh-ph-larutan-nutrisi-pada-tanaman-hidroponik/ 
Roidah \& Syamsu, I. (2014). Pemanfaatan Lahan Dengan Menggunakan Hidroponik. Jurnal Universitas Tulungagung BONOWORO, 1.

Saaid, M.F, Sanuddin, A., Ali, M., \& M.S.A. I.M Yassin. (2015). Automated pH Controller System for Hydroponic Cultivation. IEEE Symposium on Computer Applications \& Industrial Electronics (ISCAIE).

Shahrulakram, M., A., I., \& Johari, J. (2016). Water Storage Monitoring System with pH Sensor for Pharmaceutical Plants. IEEE 6th International Conference on System Engineering and Technology (ICSET).

Sudewa, B., \& Hadiatna, F. (2017). Evaluasi Sensor FIT0348 Sebagai Alat Ukur Potential Of Hydrogen (pH) Larutan. Jurnal Elektro Telekomunikasi Terapan, 4(2), 570 - 578.

Yolanda, D., Hindersah, H., Hadiatna, F., \& Triawan, M.A. (2016). Implementation of RealTime Fuzzy Logic Control for NFT-Based Hydroponic System on Internet of Things Environment. IEEE $6^{\text {th }}$ International Conference on System Engineering and Technology (ICSET). 